
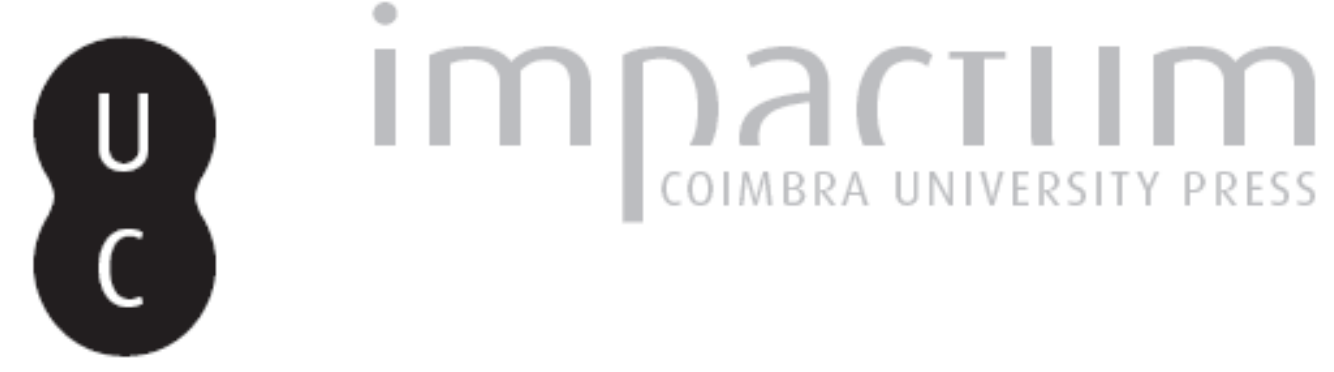

\title{
O Estado Novo brasileiro como espelho do salazarismo: autoritarismo e corporativismo na seção "crítica» da revista Brasília do Instituto de Estudos Brasileiros da FLUC (1942-1944)
}
Autor(es):
Assunção, Marcello Felisberto Morais de

Publicado por: Imprensa da Universidade de Coimbra

URL

persistente:

URI:http://hdl.handle.net/10316.2/40213

DOI:

DOI:https://doi.org/10.14195/2183-8925_34_7

\section{Accessed : $\quad$ 26-Apr-2023 12:58:33}

A navegação consulta e descarregamento dos títulos inseridos nas Bibliotecas Digitais UC Digitalis, UC Pombalina e UC Impactum, pressupõem a aceitação plena e sem reservas dos Termos e Condições de Uso destas Bibliotecas Digitais, disponíveis em https://digitalis.uc.pt/pt-pt/termos.

Conforme exposto nos referidos Termos e Condições de Uso, o descarregamento de títulos de acesso restrito requer uma licença válida de autorização devendo o utilizador aceder ao(s) documento(s) a partir de um endereço de IP da instituição detentora da supramencionada licença.

Ao utilizador é apenas permitido o descarregamento para uso pessoal, pelo que o emprego do(s) título(s) descarregado(s) para outro fim, designadamente comercial, carece de autorização do respetivo autor ou editor da obra.

Na medida em que todas as obras da UC Digitalis se encontram protegidas pelo Código do Direito de Autor e Direitos Conexos e demais legislação aplicável, toda a cópia, parcial ou total, deste documento, nos casos em que é legalmente admitida, deverá conter ou fazer-se acompanhar por este aviso.

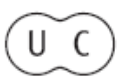



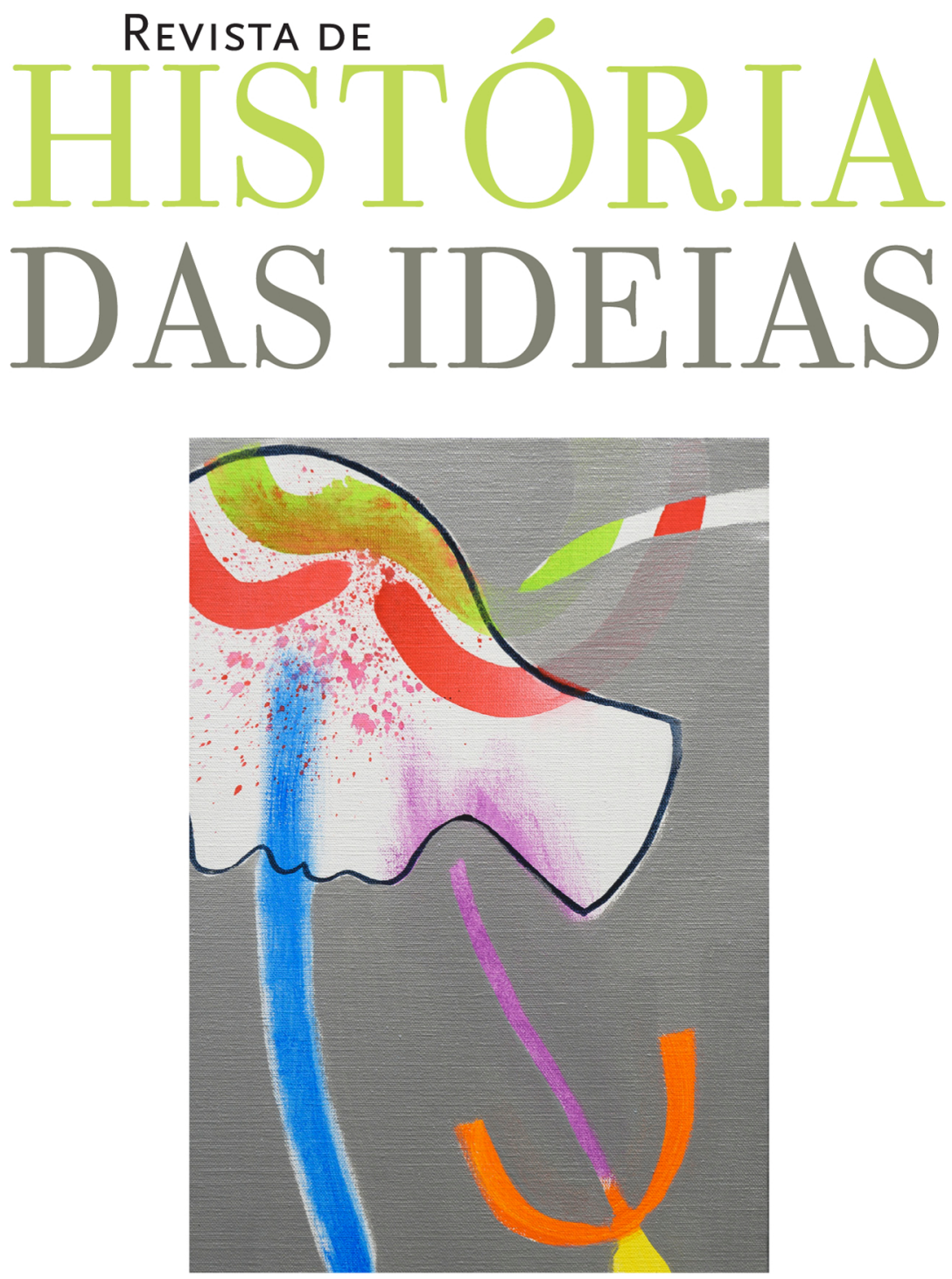

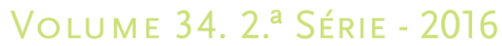




\section{O ESTADO NOVO BRASILEIRO COMO ESPELHO DO SALAZARISMO: AUTORITARISMO E CORPORATIVISMO NA SEÇÃO «CRÍTICA» DA REVISTA BRASÍLIA DO INSTITUTO DE ESTUDOS BRASILEIROS DA FLUC (1942-1944)}

THE BRASILIAN NEW STATE AS A MIRROR OF SALAZARISM:

AUTHORITARIANISM AND CORPORATIVISM IN THE

«CRITICAL» SECTION OF BRASÍLIA MAGAZINE FROM FLUC'S

BRAZILIAN STUDIES INSTITUTE

Marcello Felisberto Morais de Assunção(1)

marcellofma@gmail.com

Universidade Federal de Goiás, Brasil

Texto recebido em / Text submitted on: 03/04/2016

Texto aprovado em / Text approved on: 05/07/2016

\section{Resumo:}

Nesse texto pretendemos analisar a leitura que os intelectuais portugueses faziam do Estado Novo brasileiro (1937-1945), perscrutando essas visões por meio de algumas críticas da Revista Brasilia (1942-1944), publicada pelo Instituto de Estudos Brasileiros da FLUC. Essa leitura, segundo nossa tese, esteve vincada a certo espelhamento político entre o salazarismo e o varguismo que os intelectuais portugueses legitimaram a partir da comparação entre o

(1) Mestre e Doutorando pela Universidade Federal de Goiás (UFG), com tempo «sanduíche» no Instituto de Ciências Sociais da Universidade de Lisboa, sob orientação do Professor Doutor António Costa Pinto. 
autoritarismo e corporativismo de ambos Estados Novos no Brasil e em Portugal. Inicialmente, para melhor compreender essa construção, daremos um painel geral da Universidade de Coimbra em tempos de autoritarismo: o espaço social formativo dos intelectuais antiliberais, antissocialistas, corporativos e autoritários da revista Brasilia. Para em seguida, analisar a imagem do Estado Novo brasileiro construída nas críticas a livros brasileiros por meio de três áreas do conhecimento em particular: Pedagogia, Direito e História.

\title{
Palavras-chave:
}

Revista Brasília, Salazarismo, Varguismo, Autoritarismo, Corporativismo.

\begin{abstract}
:
In this paper we intend to analyze the reading that the Portuguese intellectuals were of the Brazilian Estado Novo, peering these visions through some reviews of the Brasilia magazine (1942-1944), published by the Instituto de Estudos Brasileiros of FLUC. This interpretation relies on the political mimesis between Salazarism and Varguism which Portuguese intelectuals legitimated by comparing the authoritarianism and corporatism on the Brazilian and Portuguese Estado Novo. First, to better understand this construction, we will give a general panel of the University of Coimbra in authoritarian times: the formative social space of the anti-liberal, anti socialists, corporativist and authoritarian intellectuals of Brasilia magazine. To then analyze the Brazilian Estado Novo image built on the criticism of Brazilian books through three particular knowledge areas: Education, Law and History.
\end{abstract}

\section{Keywords:}

Brasília Magazine, Salazarism, Varguism, Autoritarism, Corporatism.

\section{Introdução}

Francisco Carlos Palomanes Martinho e António Costa Pinto, dois importantes interpretes do corporativismo e autoritarismo, na introdução de um livro relativamente recente sobre o corporativismo no Brasil e em Portugal $^{(2)}$, explicitaram a necessidade de contornar o vácuo em torno dos estudos comparados entre o salazarismo e o varguismo. Além deste vácuo, citam a importância de analisar esses regimes por meio de suas

(2) Francisco Carlos Martinho e António Costa Pinto (ed.), Corporativismo em Português, Rio de Janeiro Civilização Brasileira, 2007. 
respectivas dinâmicas internas, compreendendo como estes expressam diferentes respostas a crise do liberalismo.

Diante deste vácuo comparativo, tentamos compreender nesse artigo a leitura/escrita que certos intelectuais portugueses contemporâneos ao varguismo, faziam do Estado Novo Brasileiro, dando ênfase na comparação que estes faziam entre o autoritarismo e corporativismo no Brasil e em Portugal. Desta forma, buscaremos perscrutar como e porque os intelectuais portugueses, no seio da universidade de Coimbra, realizavam uma série de leituras espelhadas sobre o Estado Novo no Brasil, em um período em que ambos detinham regimes de «terceira via». Essas comparações, nascidas ainda na primeira dobra do acontecimento (no tempo da memória), visavam demonstrar, como tentaremos evidenciar mais a frente, que Brasil e Portugal estavam em uma mesma «realidade política», identificada pelo corporativismo e autoritarismo.

Este espelhamento, vai ser perscrutado ao longo deste texto a partir das críticas da revista Brasilia nos anos de 1942-44, esta que foi uma publicação do Instituto de Estudos Brasileiros da Faculdade de Letras da Universidade de Coimbra ${ }^{(3)}$. A partir da análise da seção «resenhas», no período de vivencia conjunta do Estado Novo no Brasil e em Portugal, mapearemos as visões e leituras sobre o corporativismo e autoritarismo, em um diálogo que encontrou respaldo por uma grande diversidade de instituições e produções culturais nas duas margens do Atlântico. Desta forma, teremos como critério metodológico o confronto entre o conteúdo das críticas e a concepção de mundo autoritária e corporativa hegemônica em Portugal nos anos do salazarismo. Daremos foco, em particular, a três campos de conhecimento, no interior da Brasilia, que são portas de acesso para compreensão da escrita/leitura que estes intelectuais portugueses faziam dos intelectuais brasileiros, e, portanto, do Estado Novo no Brasil, a saber: pedagogia, direito e história.

Todavia, para abordamos a inserção desses intelectuais no interior de uma perspectiva autoritária e corporativa por meio das críticas, é preciso antes explorar sua materialidade institucional, ou seja, a relação entre a Universidade de Coimbra, espaço dos intelectuais que publicam na revista, e o projeto oficial do salazarismo de criação do "novo homem" português.

(3) Sobre as diversas nuanças da revista Brasilia, ver Marcello Felisberto Morais de Assunção, «Ver o outro nos próprios olhos»: A revista Brasilia e o projeto de lusitanização do Atlântico Sul, Dissertação de Mestrado, Goiânia, Universidade Federal de Goiás, 2014. 


\section{O espaço social dos intelectuais da revista Brasília: a universidade de Coimbra em tempos de autoritarismo}

A Universidade de Coimbra foi o espaço intelectual por excelência de produção e reprodução de uma concepção de mundo autoritária e corporativista. Em nenhuma outra Universidade de Portugal as relações entre produção intelectual e o salazarismo foram tão explícitas. Em um folheto sem autor, divulgado em Coimbra no início dos anos 30, discutindo o problema universitário em Portugal, encontramos claramente o sentido instrumentalizado que a Universidade deveria ter em um momento de «ressurgimento»:

Dentro do Estado Novo, não há, e não pode haver duas opiniões: Estado de tendências totalitárias, o problema universitário terá que subordinar-se, na sua solução, às diretrizes ideológicas que inspiram o Estado Novo. A Universidade terá que viver integrada no Estado Novo, e não à margem do Estado, alheio ao Estado, e quando Deus quer, inimigo do Estado. A Universidade, vivendo integrada no Estado, tem que pôr as suas atividades, todas as suas conversas ao serviço do Estado, no campo que the é próprio. Dentro da atmosfera do Estado Novo ela tem que ser nacionalista, e não internacionalista; corporativa e não liberalista; organicista e não democrática ${ }^{(4)}$.

Como aponta o estudo de António Costa Pinto ${ }^{(5)}$, não é por mero acaso que um amplo espectro da elite ministerial do salazarismo fosse formada por professores universitários de Coimbra (fundamentalmente do direito). A maioria destes, como é o caso do próprio Salazar, tiveram a sua formação em Coimbra, que desde a década de 20, tornou-se espaço de uma maioria católica, monárquica, integralista e também de alguns núcleos do nacional-sindicalismo ${ }^{(6)}$.

A Universidade de Coimbra foi alvo de uma tentativa sistemática de controle por parte do regime, a partir do domínio da imprensa da

(4) «O problema Universitário em Portugal», in Luís Reis Torgal, A universidade e o Estado Novo: O caso de Coimbra, Coimbra, Minerva, 1999, p. 88.

(5) António Costa Pinto, «O Império do professor Salazar e a elite ministerial do Estado Novo (1933-1945)», Análise Social, XXV, 157 (2000).

(6) António Costa Pinto, Os camisas azuis: ideologia, elites e movimentos fascistas em Portugal 1914-1945, Lisboa, Editorial Estampa, 1994, p. 25. 
Universidade (extinta em 1934), no controle do conteúdo ensinado e na demissão e na perseguição de professores críticos ao regime, o que também ocorre de forma mais branda em Lisboa e no Porto ${ }^{(7)}$. Tal perseguição se institucionaliza a partir de dois decretos-lei: o de n ${ }^{\circ} 22.469$ de 11 de abril de 1933 e no $^{\circ} 27.00314$ de dezembro de 1936 . O primeiro explicita o objetivo da censura ${ }^{(8)}$ :

A censura terá somente por fim impedir a perversão da opinião pública na sua função de força social e deverá ser exercida por forma a defendê-la de todos os fatores que a desorientem contra a verdade, a justiça, a moral, a boa administração e o bem comum, e a evitar que sejam atacados os princípios fundamentais da organização da sociedade ${ }^{(9)}$.

Já o segundo decreto-lei se refere mais diretamente aos funcionários públicos, e por extensão aos professores universitários, que eram obrigados a fazer o seguinte juramento público: «Declaro por minha honra que estou integrado na ordem social estabelecida pela Constituição política de 1933, com activo repúdio do comunismo e de todas as ideias subversivas» ${ }^{(10)}$. A militância anticomunista foi um fato rotineiro da vida de Coimbra, sendo um elemento agregador e mobilizador de uma série de grupos.

É no seio deste espaço social imerso em um nacionalismo ufanista que se formula o ambiente para comícios anticomunistas em Coimbra, mobilizações de instituições com imbricadas relações com a direita radical (Cruzada D. Nuno Álvares Perreira e a Legião Portuguesa) e na consagração de diversos intelectuais (dois reitores de posição falangista

(7) Luís Reis Torgal, «Estado Novo e intolerância: repressão e reprodução ideológica», in Maria Luiza Tucci Carneiro (ed.), Tempos de fascismos: ideologia-intolerância-imaginário, São Paulo, Editora da Universidade de São Paulo, 2010, p. 75.

(8) Censura que como mostra Luís Reis Torgal, em diversos trabalhos, se expande para uma série de instituições da sociedade civil, editoras, a literatura oficial (consagrada através de prêmios), as casas do povo, os sindicatos nacionais, as bibliotecas do povo, os jornais (A Verdade, Diário da Manhã e o Diário de Notícias), o rádio (Emissora Nacional), o cinema. A censura também ocorre dentro da sociedade política: no Secretariado de Propaganda Nacional, nos tribunais militares especiais, o PVDE (Polícia de Vigilância do Estado), PIDE (Polícia Internacional de Defesa do Estado), etc.

(9) Artigo n. 3 do decreto-lei n. 22.469 in Luís Reis Torgal, «Estado Novo e intolerância..., cit., p. 112-113.

(10) Decreto-lei n. 27.00314 in Luís Reis Torgal, «Estado Novo e intolerância..., cit., p. 115 . 
são consagrados com doutor honoris: Felipe Gil Casares e Leonardo Perro) e estadistas (o próprio Franco) que estão de acordo com uma perspectiva de «terceira via» ${ }^{(11)}$.

Há, portanto, uma identificação muito clara e ativa entre a concepção de mundo oficial do salazarismo (autoritária e corporativa) e aquela que aparece na grande maioria dos intelectuais de Coimbra ${ }^{(12)}$. A identificação da Universidade de Coimbra com a concepção de mundo oficial (autoritária, corporativa, imperialista e cristã) pode ser visibilizada em uma série de produções culturais do período, como é o caso da Revista Portuguesa de História, o Boletim da Faculdade de Direito, a revista Biblos, o Boletim do Instituto de Estudos Germânicos e o Boletim do Instituto de Estudos Franceses, e, por fim, a própria revista Brasilia. Poderíamos dizer que estas produções, e grande parte da intelectualidade da Universidade de Coimbra, estão imersas em um projeto de hegemonização cultural que a política do espírito institucionaliza desde a fundação do Secretariado de Propaganda Nacional em 1933, que tem António Ferro como seu principal protagonista.

A política cultural oficial salazarista, verbalizada por Ferro em diversos momentos, pensava o espírito lusitano como matéria-prima a ser moldada segundo a defesa de um «ressurgimento», concepção tão cara aos fascismos. Tal política busca instituir, em um âmbito estritamente estético, uma concepção harmônica e corporativista das relações sociais que supostamente dissolve o conflito de classe. Para realizar tal pretensão, o Estado Novo português projeta em seus discursos ao longo dos anos 30 e 40 um ethos português, condizente com essa perspectiva da harmonia social. Difunde no período um discurso agressivo e combativo, apesar das suas fissuras e nuanças internas, que produz e institui uma memória histórica, de tipo nacional, que pretende ser ontológica e científica frente a qualquer memória desviante ${ }^{(13)}$.

Essa pretensão totalizante do projeto cultural do Estado Novo será materializada a partir da atração e adesão de agentes e também da montagem de um dispositivo cultural que exerce o papel fundamental

(11) Luís Reis Torgal, Estado Novo, Estados Novos, Coimbra, Imprensa da Universidade de Coimbra, 2009, p. 114.

(12) Luís Reis Torgal, Estado Novo..., cit., p. 112.

(13) Fernando Rosas, «O salazarismo e o homem novo: ensaio sobre o Estado Novo e a questão do totalitarismo», Análise Social, XXXV, 157 (2001), p. 1033. 
de organização da propaganda nacional e da cultura ${ }^{(14)}$. Esse dispositivo cultural buscou criar um processo de «regeneração nacional», a fim de reconduzir os portugueses à sua «ordem natural», combatendo toda e qualquer «degenerescência do espírito», a partir da «reeducação», fazendo-os encontrar com a sua «essência natural» ${ }^{(15)}$.

A construção de um ser nacional lusitano foi, portanto, uma peça chave no discurso da intelligentsia portuguesa desde a crise institucional que se arrastou desde o fim do século XIX, e, em particular, a partir do Ultimatum de 1890. A regeneração das glórias lusitanas por meio da reconstrução nacional, através do império, do corporativismo e do autoritarismo, esteve presente nesse processo de «olhar para dentro» nos tempos da política do espírito salazarista. Este engajamento e adesão dos intelectuais à realidade nacional por meio da invocação de um Estado capaz de unificar e harmonizar as distintas perspectivas é um indício de uma certa homologia do campo político e intelectual.

Estas representações do político encontram-se em Portugal, e, também no Brasil, em tempos de autoritarismos, como aspectos de uma cultura política que competia uma grande responsabilidade aos intelectuais na sua intervenção pública na construção da nação. A figura paradigmática deste momento é, portanto, a do «intelectual profeta», aquele que detém como «Vocação» o desvelar do «subconsciente coletivo», como afirmavam um Azevedo de Amaral, Oliveira Viana e outros pensadores do período ${ }^{(16)}$.

Desta forma, não é arbitrário que em uma revista de cultura lusobrasileira como a Brasilia, e, também a Atlântico, apareçam intelectuais, portugueses e brasileiros, de diversas matizes na busca por forjar uma cultura nacional que trata de forma elogiosa as práticas do autoritarismo de ambos regimes. Na realidade, não há só elogios no caso particular

(14) Jorge Ramos do Ó, Os anos de ferro: dispositivo cultural durante a Política do Espírito, 1933-1949, $1^{\text {a }}$ ed., Lisboa, Estampa, 1999, p. 74.

(15) Fernando Rosas, «O salazarismo e o homem novo..., cit., p. 1034.

(16) Azevedo de Amaral (1881-1942), intelectual de perspectiva autoritária e corporativa do período, expressa muito bem essa visão dos intelectuais: «Emergidos da coletividade como expressões mais lúcidas do que ainda não se tornou perfeitamente consciente no espírito do povo, os intelectuais são investidos da função de retransmitir às massas sob forma clara e compreensiva o que nelas é apenas uma ideia indecisa e uma aspiração mal definida. Assim a elite cultural do país tornou-se no Estado Novo um órgão necessariamente associado ao poder público como centro de elaboração ideológica e núcleo de irradiação do pensamento nacional que ela sublima e coordena» (Azevedo de Amaral in Monica Pimenta Velloso, Os intelectuais e a política cultural do Estado Novo, Rio de Janeiro, Editora FGV, 1987, p. 18). 
destes Estados Novos, mas, uma concepção de mundo comum no que concerne aos diagnósticos e soluções para os "problemas nacionais», a saber: a) a rejeição ao liberalismo e da democracia política, b) a ideia de que os intelectuais são uma elite dirigente acima do social, c) a invocação sistemática da ação do estado na cultura, política e economia; d) uma concepção de mundo corporativista própria de um ideário vincado na utopia conservadora das "harmonias sociais". Esta unidade das representações do fenómeno político, tendem a ser compartilhadas pela intelligentsia no Brasil e em Portugal nos anos da vaga autoritária (décadas de 1920-40)(17), e se reproduzem institucionalmente, como veremos logo a frente, no caso da própria revista Brasilia.

\section{Em defesa dos Estados Novos: representações do Brasil nas resenhas da intelligentsia «autoritária» e «corporativa» da revista Brasília (1942-1944)}

Nas resenhas produzidas na revista Brasilia, encontramos uma presença recorrente de livros brasileiros selecionados que defendem em diversos âmbitos uma concepção de mundo «autoritária» e «corporativa». Entre os temas deparamos com textos sobre a pedagogia «renovada» do Estado Novo no Brasil em autores como Francisco Campos e Fernando Azevedo, até temas como a política eugenista ou estudos sobre a ascensão de Vargas e as suas transformações em um âmbito econômico e político. Dentre estas críticas, daremos ênfase às três grandes áreas discutidas no seio da Brasilia: Pedagogia, Direito e História.

O projeto pedagógico varguista foi amplamente discutido ao longo das críticas da revista Brasilia. Um aspecto recorrente na discussão dos livros resenhados, foi a questão da «escola nova» no Brasil, e, portanto, o projeto de formação de uma elite técnica, capaz de «guiar» a nação para a sua modernização institucional, identificada tanto pela racionalização da burocracia como pela criação de infraestruturas. Para estes intelectuais no Brasil e em Portugal, a educação era também um instrumento para a moralização cívica de um «novo homem» moldado, pelo Estado.

(17) Para uma análise global da vaga autoritária dos anos 20-40 em Portugal, ver António Costa Pinto, «O Estado Novo português e a vaga autoritária dos anos de 1930 do século XX», in Francisco Carlos Matinho e António Costa Pinto, Corporativismo em Português, Rio de Janeiro, Civilização Brasileira, 2007. 
Um exemplo claro desta visão pedagógica, pode ser encontrada na resenha de Emile Planchard ao livro de Humberto Grande A pedagogia no Estado Novo, como o mesmo reitera:

A pedagogia no Estado Novo é a educação dirigida, capaz de renovar e organizar uma sociedade pela cultura; é a pedagogia da disciplina e da autoridade que quer formar no espírito das novas gerações uma mentalidade vigorosa e confiante, desejando esclarecer a inteligência brasileira para a compreensão exacta dos grandes problemas nacionais ${ }^{(18)}$.

A exortação das práticas pedagógicas no Brasil por Emile Planchard, revelam a proximidade entre o conceito de pedagogia reproduzido por intelectuais no Brasil e os pressupostos da «Política do Espírito» salazarista, fundamentalmente, no que concerne a sua visão das massas como uma matéria-prima a ser moldada, por meio de políticas culturais. Para Planchard, em sua leitura do livro de Humberto Grande, a pedagogia de ambos Estado Novos buscava os fundamentos científicos para a realização de uma ampla intervenção pública, com o intuito de transformar os pressupostos da antiga prática pedagógica, ainda muito liberal e individualista ${ }^{(19)}$. A despeito de criticar o livro de Humberto por não trazer nenhuma novidade significativa, elogia a sua capacidade de explicar sinteticamente as inovações que o conceito de pedagogia moderna, oriundo da «Escola Nova», traz ao público brasileiro ${ }^{(20)}$. A retórica pedagógica «bacharelesca», própria do período liberal, deveria desaparecer em prol de práticas, por meio do Estado, que direcione uma verdadeira «renovação nacional» da educação desde a infância até a fase adulta ${ }^{(21)}$.

A mesma crítica a pedagogia liberal e o elogio com relação as práticas pedagógicas no Brasil, aparece em uma outra resenha de Emile Planchard ao livro A educação pública em S. Paulo de Fernando de Azevedo, um dos principais idealizadores da renovação pedagógica do varguismo. Planchard elogia a grande capacidade analítica de Azevedo, exortando as suas propostas para a transformação da educação pública no Brasil

(18) Humberto Grande in Emile Planchard, «A pedagogia no Estado Novo (Humberto Grande)», Revista Brasilia, Crítica, II (1943), p. 877.

(19) Emile Planchard, «A pedagogia no Estado Novo..., cit., p. 877.

(20) Emile Planchard, «A pedagogia no Estado Novo..., cit., p. 879.

(21) Emile Planchard, «A pedagogia no Estado Novo..., cit., p. 880. 
por meio da invocação de uma proposta unitária para a organização pedagógica, que teria o Estado como seu maior protagonista.

Afirma ainda, que as deficiências educacionais que Azevedo encontra em seu estudo da instrução nacional, estão em processo de transformação em razão da institucionalização da «revolução nacional que se completou no Brasil» desde a emergência do Estado Novo em $1937^{(22)}$. Explicita que o maior mérito do trabalho de Azevedo é a conciliação entre a sua prática como diretor geral da instrução e os seus escritos pedagógicos. Finaliza sua resenha considerando Azevedo um dos principais protagonistas da renovação pedagógica estado-novista ${ }^{(23)}$. Aliás, essa laudação de Emile Planchard, belga radicado em Portugal, à renovação pedagógica no Brasil não é arbitraria, o mesmo foi o principal divulgador da Escola Nova em Portugal, introduzindo uma pedagogia que buscasse fomentar as «solidariedades sociais», como é próprio de sua matriz corporativista de inspiração durkheimiana.

Em uma outra resenha no mesmo volume, Duque Vieira analisa a obra de Francisco Campos Educação e Cultura, outro arauto da renovação pedagógica do Estado Novo no Brasil. Inicia sua resenha elogiando as virtudes de Campos como «homem público», que são refletidas em suas intervenções publicadas nesse livro ofertado pela Seção Brasileira do Secretariado de Propaganda Nacional ao Instituto de Estudos Brasileiros. Segundo Vieira os discursos de Campos enquanto diretor da Secretaria da Instrução, e os mais contemporâneos como Ministro da Educação Federal, são páginas de verdadeiro brilhantismo de um estadista-escritor pois, os seus escritos não são mera retórica mas, espelhos de sua própria prática enquanto homem de Estado ${ }^{(24)}$. Ainda sobre o livro de Campos, Vieira cita a importância que a «formação moral e patriótica» deve ter na reforma da instrução nacional no Brasil. Essa reforma, segundo Vieira em sua interpretação de Campos, deveria criar uma educação que não forme meramente «bacharéis» (como é próprio da pedagogia de até então), mas quadros da elite capazes de orientar os rumos da nação ${ }^{(25)}$.

(22) Emile Planchard, «A educação pública em São Paulo (Fernando de Azevedo)», Revista Brasilia, Crítica, I (1942) p. 824.

(23) Emile Planchard, «A educação pública em São Paulo..., cit., p. 824.

(24) Duque Vieira, Educação e cultura (Francisco Campos), Revista Brasilia, Crítica, III (1946), p. 909.

(25) Duque Vieira, «Educação e cultura..., cit., p. 911. 
Para o crítico, a renovação pedagógica orientada no Brasil, e, também em Portugal, ao orientar-se a partir de suas respectivas particularidades nacionais e culturais, gera por si uma autonomia destas nações, até então muito presas aos «estrangeirismos», que eram, para Vieira, verdadeiros empecilhos à autonomia nacional ${ }^{(26)}$. Encerra sua resenha, explicitando que essa autonomia faria com que Brasil e Portugal fossem capazes de ocupar o seu lugar de protagonistas de um «novo eixo mundial» que teria como epicentro o Atlântico e a língua e a cultura luso-brasileira como constitutivas desta nova civilização ${ }^{(27)}$.

A apologia ao projeto pedagógico destes autores pelos resenhistas portugueses, tem uma estrutura comum: a defesa intransigente de um modelo de «instrução nacional» arregimentado pelo estado com um forte teor elitista e corporativista. Este projeto autoritário e corporativo, é visto por estes autores como um «desdobramento natural do tempo", portanto, como uma realidade dos regimes que buscam uma modernização institucional por meio daquilo que existe como mais «científico» no período. Entretanto, não é somente no campo pedagógico que estas noções aparecem, no campo jurídico e historiográfico há uma repetição recorrente das «soluções» aos problemas nacionais pelos brasileiros lidos pelos portugueses, como o elogio apologético a estas mesmas resoluções.

Em uma crítica de José de Alberto Reis ao Código do Processo Civil Brasileiro de 1937 redigido por Pedro Batista e revisado por Francisco Campos, há uma análise laudatória do autoritarismo das resoluções estado-novistas no âmbito jurídico, e, em particular, uma exortação explícita a constituição 1937 («Polaca»). Inicia sua crítica avaliando positivamente a substituição de «um regime da pluralidade para a unidade do código civil» orquestrada pelo Estado Novo de Vargas, sobre o protagonismo de Francisco Campos ${ }^{(28)}$. Reitera sua defesa a estas mudanças constitucionais citando uma série de reflexões de Francisco Campos que em um relatório afirma que o processo civil deixou de ser «instrumento das classes privilegiadas» para assim «assumir uma feição de cunho eminentemente popular»(29).

(26) Duque Vieira, «Educação e cultura..., cit., p. 912.

(27) Duque Vieira, «Educação e cultura..., cit., p. 912.

(28) José Alberto Reis, «Código de processo civil brasileiro (Francisco Campos)», Revista Brasilia, Crítica, I (1942), p. 830.

(29) José Alberto Reis, «Código de processo civil brasileiro..., cit., p. 830. 
Segundo o crítico essas mudanças visavam a simplificação e universalização do processo jurídico, superando os entraves de uma institucionalidade burocrática que propiciava, em sua lentidão, a vitória das «classes dominantes» frente as massas, almejando por meio desta transformação a harmonização entre as partes ${ }^{(30)}$. Essa «harmonia» seria alcançada por meio de um maior fortalecimento da figura do juiz que agora deve intervir contra o «privatismo» e «individualismo» para assim ter uma solução de fato «harmônica» ${ }^{(31)}$. Esta concepção das «harmonias sociais», implícita no discurso e na constituição, analisada por Reis, aparece ainda de forma mais explícita na citação que o mesmo destaca do relatório supracitado de Campos:

A concepção duelistica substitui-se a concepção autoritária: o processo deixou de ser encarado como um instrumento de luta entre particulares e passou a ser considerado como instrumento de investigação da verdade e da distribuição da justiça. E como distribuição da justiça é uma das funções e uma prerrogativa do estado, daí vem que este não pode assistir, impassível e inerte, o desenrola do drama judiciário: tem de intervir nele activamente como interessado, para que o resultado corresponda ao fim, para que triunfe a verdade e a justiça, em vez de triunfar a força ou a astúcia ${ }^{(32)}$.

Desta forma, a «verdade» constituída no processo jurídico, não seria mais como era no processo duelístico a cargo das partes, mas da intervenção do juiz, representante do Estado, o único capaz, segundo Reis, de harmonizar os conflitos segundo «uma construção científica» "(33). Essa justiça distributiva, superaria, portanto, a «ficção liberal» que fazia uso do «poder público» para interesses «privados», «individuais». Ainda afirma, que esta concepção «autoritária» e erroneamente enquadrada como «fascista», pois apesar de sua proximidade a aquilo que se encontrava nos Estados «totalitários» há algumas diferenças que devem ser resguardadas ${ }^{(34)}$.

Reitera que a despeito da figura do juiz forte e ativo este só deve intervir, nos regimes ditos autoritários, para impedir «desequilíbrios

(30) José Alberto Reis, «Código de processo civil brasileiro..., cit., p. 830.

(31) José Alberto Reis, «Código de processo civil brasileiro..., cit., p. 830.

(32) José Alberto Reis, «Código de processo civil brasileiro..., cit., p. 831.

(33) José Alberto Reis, «Código de processo civil brasileiro..., cit., p. 832.

(34) José Alberto Reis, «Código de processo civil brasileiro..., cit., p. 833. 
aplicando a justiça». Na verdade, para este o código civil, em particular, era tributário, e, portanto, mais próximo, do Código Civil português de 1936, afirmando que certos artigos são diretamente inspirados, apesar de não citá-los comparativamente na crítica. Entretanto, entra em dissenso quando Campos afirma a sua interpretação do processo jurídico sobre a herança dos publicistas americanos, não afirmando a autoridade dos portugueses na construção do código português.

A despeito destes desvios pontuais, a leitura de Reis é otimista se sobressaindo a defesa intransigente ao autoritarismo e corporativismo que a Constituição de 1937 representava no Brasil, espelhando até uma certa proximidade entre Portugal e Brasil no âmbito jurídico. Esta laudação não é arbitrária, Reis foi autor do Código de Processo Português, de 1939, e era também professor de Direito da Faculdade de Coimbra e Presidente da Assembleia Nacional. O que o coloca em um lugar institucional bastante propício para uma leitura positiva da institucionalidade proposta pelo Estado Novo no Brasil, em clara, consonância com o regime português. Esta proximidade é ainda mais clara no âmbito historiográfico.

A historiografia publicada na Brasilia não só afirmou um «olhar comum» em um passado longínquo, mas também buscou no presente aspectos que vinculassem intimamente Brasil e Portugal. Essa aproximação política foi marcante no que concerne aos três primeiros volumes $(1942,1943,1944 / 46)$, mesmo porque essa produção emerge no período em que o Estado Novo brasileiro e português estão no auge de sua aproximação política e cultural. Além destes intelectuais compartilharem uma visão consensual sobre o legado português no mundo, também coadunam com o pensamento autoritário, corporativo, antissocialista, antiliberal e antidemocrático.

Em geral, as obras historiográficas resenhadas sobre o Estado Novo brasileiro abordavam a questão da ascensão do varguismo, pensando neste sempre como um contraponto ao liberalismo. A sua grande maioria afirmava explicitamente sua posição dentro dos marcos de uma concepção «autoritária» e "corporativa», o que fazia com que esses autores fossem exaustivamente elogiados pelos críticos. Além de tudo, é frequente também a comparação entre as práticas do Estado Novo brasileiro com o português, reiterando um certo espelhamento entre os regimes.

Um exemplo disso é a resenha de Duque Vieira do livro escrito por Azevedo de Amaral, Getúlio Vargas Estadista, Rio de Janeiro, ed. dos Irmãos 
Pongetti, 1941. O resenhista ressalta deste livro, uma biografia de Getúlio Vargas e de seu tempo, a constante apologia a Vargas, que é amenizada por este estudo ser "filho da verdadeira sinceridade e de visível convicção»"(35). Um elemento ressaltado pelo resenhista como ponto de referência de consenso é a proximidade de olhares e de práticas de estado entre Brasil e Portugal que o contexto evidenciado no livro explicita:

Como é sabido, há muitos pontos de semelhança entre a moderna orientação política do Brasil e de Portugal. Verificá-lo é um grato prazer para os Portugueses, para quem é caro tudo quanto diz respeito ao Brasil e que veem com alegria tudo quanto assemelhe ou aproxime os dois países, sobretudo, quando eles chegam ambos, como agora, por conclusão autônoma a situações pelo menos parcialmente idênticas ${ }^{(36)}$.

Para Duque Vieira, esta situação "parcialmente idêntica» é a própria crítica ao liberalismo e à semelhança como em ambos países a questão social e econômica estava sendo gerida, a partir de um estado que se colocava «em um plano superior à controvérsia travada entre o capital e o trabalho» ${ }^{(37)}$, rompendo por meio de uma série de práticas com a supremacia do privado sobre o público. Registra, fundamentado em Azevedo de Amaral, que a resolução deste conflito se direcionava a partir de um Estado que impusesse ao capital e ao trabalho o conceito do «primado do bem público sobre todas as conveniências de caráter privado» ${ }^{(38)}$. Segundo o crítico, esta semelhança entre ambos regimes era também compartilhada na política financeira (explicitando a política protecionista de Vargas como semelhante à de Salazar) como também em razão da proximidade de ambos como estadistas, pois os dois supostamente incorporam e sintetizam «as qualidades e a maneira de ser de seu povo» ${ }^{(39)}$.

Duque Vieira finaliza sua crítica registrando que o historiador futuro deve direcionar seu olhar para a «revolução operada por Getúlio Vargas», já que esta, por suas «inúmeras virtudes» preservou a unidade nacional e afirmou a autonomia e soberania do Brasil frente à hegemonia externa

(35) Duque Vieira, «Getúlio Vargas Estadista (Azevedo de Amaral)», Revista Brasilia, Crítica, III (1946), p. 915.

(36) Duque Vieira, «Getúlio Vargas Estadista..., cit., p. 916.

(37) Duque Vieira, «Getúlio Vargas Estadista..., cit., p. 917.

(38) Duque Vieira, «Getúlio Vargas Estadista..., cit., p. 917.

(39) Duque Vieira, «Getúlio Vargas Estadista..., cit., p. 917. 
(fundamentalmente o pan-americanismo), antagonizando-se à política liberal em prol da «reconquista da unidade interna do Brasil». Ainda afirma, que esta reconquista significaria para o Brasil ser mais «igual a si mesmo», ou seja, ser mais fiel à sua herança, e, portanto «mais simpáticos para os seus amigos deste lado oriental do Atlântico» ${ }^{(40)}$.

A ascensão do varguismo é vista pelos resenhistas (através dos livros selecionados) em uma dimensão «fatalista» e «natural». Vargas e Salazar são considerados como expressões, segundo o discurso dominante, de um Estado «renegenerado» que superou, por meio da centralização do poder em suas mãos, o período «negro» do liberalismo. Esta interpretação consagrada nos manuais didáticos e na historiografia oficial é explícita na resenha de Almeida e Souza ao livro de J. de Mattos Ibiapina intitulado O Brasil de ontem e de hoje, publicado pelo Departamento de Imprensa e Propaganda.

O resenhista inicia seu texto elogiando o livro de Ibiapina por ser uma crítica contra os políticos que levaram o Brasil ao «descalabro» e uma defesa intransigente da ação de Vargas em seus diversos aspectos ${ }^{(41)}$. Almeida considera que a crise descrita pelo autor não é peculiar apenas ao Brasil, mas «um fenômeno geral, atingindo até uma maior intensidade nesta velha Europa, teatro de experiências dolorosas em busca de um rumo político e social definido» ${ }^{(42)}$.

Ainda sobre a crise, afirma que as resoluções tomadas mediante o caos geral do liberalismo foram em alguns casos exageradas no que concerne à «estatolatria» e ao culto da filosofia da força ${ }^{(43)}$. Desta forma, critica o nazismo e os regimes que considera como «totalitários», enquadrando o caso português e brasileiro como fora dessa órbita. Esta diferenciação é recorrente não só nos intelectuais portugueses e brasileiros do período, mas também no discurso dos homens do estado que contrapõem o fascismo («totalitarismo», própria de «povos violentos») à uma «ditadura de direito» própria de um «povo pacifico». Como reitera o próprio Salazar:

A nossa ditadura aproxima-se, evidentemente, da Ditadura fascista no reforço da autoridade, na guerra declarada a certos princípios da

(40) Duque Vieira, «Getúlio Vargas Estadista..., cit., p. 918.

(41) Almeida Souza, «O Brasil de ontem e de hoje (J. de Mattos Ibiapina)», Revista Brasilia, Crítica, III (1946), p. 919.

(42) Almeida Souza, «O Brasil de ontem e de hoje..., cit., p. 919.

(43) Almeida Souza, «O Brasil de ontem e de hoje..., cit., p. 919. 
democracia, no seu caráter acentuadamente nacionalista, nas suas preocupações de ordem social. Afasta-se, porém, nos seus processos de renovação. A ditadura fascista tende para um cesarismo pagão, para um estado novo que não conhece limitações de ordem jurídica ou moral, que marcha para o seu fim, sem encontrar embaraços nem obstáculos [...] O Estado Novo português, ao contrário, não pode fugir, a certas limitações e ordem moral que julga indispensável manter, como balizar, à sua ação reformadora [...] As nossa leis são menos severas, os nossos costumes menos policiados, mas o Estado, esse, é menos absoluto e não proclamamos onipotente $^{(44)}$.

Voltando a crítica, Almeida ao analisar a História do Brasil recente interpretada por Ibiapina, critica as ações das lideranças do Brasil republicano, uma vez que, ao tentarem implantar ideias «estranhas à realidade brasileira» estes não souberam dar continuidade à herança da monarquia de uma "pátria unida e forte» ${ }^{(45)}$. Segundo o crítico, a crise do Brasil republicano deve-se à política «privatista» dos estados. Esta política é reforçada pela Constituição de 1891 através de seu «utopismo transposto» ${ }^{(46)}$. O caso do café e da borracha são exemplos claros, para Almeida, de como o Brasil se tornou uma colônia financeira internacional, um «feudo do capitalismo estrangeiro» ${ }^{(47)}$. Afirma que se não fosse a «revolução» operada por Vargas, o país caminharia a «passos largos para a derrocada social» ${ }^{(48)}$. Elogia o «amor pátrio» de Ibiapina em sua descrição das diversas medidas que Vargas implanta para a superação da crise: lei de proteção ao trabalho, lei da aposentadoria, lei da sindicalização, lei das oito horas de trabalho e o confronto com os «privatistas paulistas» e a consequente centralização do poder político e econômico ${ }^{(49)}$.

Esta perspectiva da história recente, que enquadra o passado recente, liberal-individualista, como «negro», e afirma um presente «renovado» e «regenerado» é própria de uma certa noção de tempo histórico

(44) António Oliveira Salazar, Salazar: Discursos, notas, relatórios, teses, artigos e entrevistas, Lisboa, Editorial Vanguarda, 1955, p. 74.

(45) Almeida Souza, «O Brasil de ontem e de hoje..., cit., p. 920.

(46) Almeida Souza, «O Brasil de ontem e de hoje..., cit., p. 921.

(47) Almeida Souza, «O Brasil de ontem e de hoje..., cit., p. 921.

(48) Almeida Souza, «O Brasil de ontem e de hoje..., cit., p. 922.

(49) Almeida Souza, «O Brasil de ontem e de hoje..., cit., p. 923. 
dominante do período, que vê a história nos marcos de «momentos áureos» (o «hoje») e momentos «decadentes» (o «ontem»), tendo os primeiros como «exemplos» para práticas futuras. Tal visão da história não aparece somente na crítica ao livro de Ibiapina, mas também em pelo menos duas outras resenhas que se remetem à superação da crise econômica do Brasil.

Na primeira resenha, escrita por Fernando Pinto Loureiro ao livro de Luís Dias Rollemberg Aspectos e perspectivas da economia nacional, publicado como parte da coleção «Decenal da Revolução Brasileira», há uma análise de história econômica do Brasil recente. Evidencia a mudança recente no Brasil de uma política econômica particularista para uma verdadeira política nacional em $\operatorname{Vargas}^{(50)}$. O crítico elogia a visão de Rollemberg sobre o passado e o presente do Brasil, reiterando a perspectiva de um passado recente caótico, em razão do privatismo protagonizado pelos cafeicultores, sendo somente com Vargas o início de um longo caminho para a autonomia do Brasil ${ }^{(51)}$.

De forma análoga a esta resenha, Afonso Rodrigues Queiró, no livro As autarquias e as sociedades de economia mixta no Estado Novo, publicada pelo Departamento de Imprensa e Propaganda, critica, fundamentado na leitura de Queiró, o que ele denomina como «Estado individualista-liberal» em prol de um «Estado intervencionista», que lute contra o privatismo, segundo uma perspectiva dirigista da política e da economia ${ }^{(52)}$. Regista ainda que o Estado intervencionista deve harmonizar o bem público, "coletivo», com os distintos interesses privados ${ }^{(53)}$. Para Queiró, com a proclamação da República há uma dominância negativa do poder privado sobre o poder público, a despeito da tentativa de inúmeros indivíduos no seio do Estado «preocupados com o bem comum», e ainda afirma que:

[a] Economia entregue a si própria, colocada ao lado ou acima do Estado, dominando-o e enfraquecendo-o, justificou plenamente a revolução de 1930, expressão da necessidade nacional de um Estado

(50) Fernando Pinto Loureiro, «Aspectos e perspectivas da economia nacional (Luís Dias Rollemberg)», Revista Brasilia, Crítica, II (1943), p. 884.

(51) Fernando Pinto Loureiro, «Aspectos e perspectivas da economia..., cit., p. 884.

(52) Afonso Rodrigues Queiro, «As autarquias e as sociedades de economia mixta no Estado Novo (Eryma Carneiro)», Revista Brasilia, Crítica, II (1943), p. 797.

(53) Afonso Rodrigues Queiró, «As autarquias e as sociedades de economia..., cit., p. 798. 
forte e autoritário, de um Estado Novo, disposto a agir positivamente, em especial no domínio econômico ${ }^{(54)}$.

Para o crítico, é com as Constituições políticas de 1934 e 1937 que se concretizam os princípios programáticos do Estado Novo Brasileiro, tendo como base da ideia de harmonização do público com o privado, citando a Constituição para reiterar seu argumento. Em sua leitura da obra de Eryma, essa suposta harmonização descrita pelo autor invade também o âmbito da representação corporativa, segundo este, muito mais «democrática» que a representação meramente política liberal, criando assim uma ação conjunta entre as diversas «forças econômicas», as «forças vivas da nação», em prol do «crescimento nacional» ${ }^{(55)}$. Para Queiró, esta integração da sociedade, por meio das corporações, e, em particular no seio do «Conselho da Economia Nacional», é análoga ao que o governo português fazia por meio da «Câmara corporativa portuguesa», e mesmo da «Câmara dos fáscios» na Itália ${ }^{(56)}$.

A defesa intransigente à concepção de mundo autoritária e corporativa é ainda mais explícita quando esta é confrontada por uma voz de dissenso. Duarte de Montalegre, em uma resenha à revista do Arquivo Municipal de São Paulo, destaca o artigo de António Piccarolo «História das doutrinas políticas». Tece diversas críticas à posição «difamatória» do autor em sua análise aos regimes «totalitários e autoritários». Afirma que a despeito deste artigo ser um trabalho sério até a primeira e segunda parte da sua obra, na terceira, quando procura analisar as doutrinas do nacionalsocialismo e da democracia «deixa-se por completo obcecar pelo paroxismo de suas latrias e das suas fobias políticas» ${ }^{(57)}$. Piccarolo, segundo a crítica de Montalegre, ao contrário de uma atitude própria de um «homem de ciência», teve um comportamento sectário ao tratar de forma elogiosa a democracia e negar por completo as doutrinas do nacional-socialismo ${ }^{(58)}$.

Para Montalegre, o historiador deve se limitar aos fatos políticos, e «narrá-los tais como aconteceu» visto que segundo a sua perspectiva essencialista «[o]s factos... são factos e não vale deformar o seu sentido

(54) Afonso Rodrigues Queiró, «As autarquias e as sociedades de economia..., cit., p. 800.

(55) Afonso Rodrigues Queiró, «As autarquias e as sociedades de economia..., cit., p. 801.

(56) Afonso Rodrigues Queiró, «As autarquias e as sociedades de economia..., cit., p. 802.

(57) Duarte Montalegre, «Revista do Arquivo Municipal (Antônio Piccarolo)», Revista Brasilia, Crítica, III (1946) p. 921-952, 938.

(58) Duarte Montalegre, «Revista do Arquivo Municipal..., cit., p. 939. 
positivo, mesmo quando eles reduzem o pensamento doutrinário a sua expressão mais simples» ${ }^{(59)}$. Mais à frente, cita Piccarolo a fim de demonstrar a sua parcialidade, e, portanto, falta de cientificidade com relação à sua análise: «Fascismo e Nazismo, de facto, não são doutrinas mas simplesmente negações dos princípios fundamentais, que constituem o glorioso patrimônio político dos últimos séculos, conquistado através das gloriosas lutas do pensamento e da ação» ${ }^{(60)}$. Considera tal interpretação como própria de um «arrivista» ou «demagogo» e não de um historiador sério, mesmo porque, segundo Montalegre, o problema não é, se o mesmo é anti-feixista, mas se ele não se limita aos «domínios da história das ideias», sem «formular juízos de valor», reiterando que, se um outro intelectual se manifestasse da mesma forma que Piccarolo com relação ao fascismo e nazismo, procederia também de forma "parcial» e «deformada» ${ }^{(61)}$. Termina o texto afirmando que em razão da fobia de Piccarolo a tudo que «não seja democrático», acaba sendo mais apologista dos seus «ideais doutrinários» do que propriamente historiador ${ }^{(62)}$.

Essa contradição entre o discurso da «neutralidade»e «imparcialidade» e a defesa intransigente ao regime está presente de forma unânime nas narrativas da Brasilia. Ao revelarem o Brasil a Portugal, buscavam uma imagem da História do Brasil que correspondessem a uma concepção de mundo marcadamente imperialista, autoritária e corporativa. Todo critério de seleção e avaliação foi orientado pela defesa de uma concepção de mundo oficial formada por certos valores, constitutivos de um certo caráter lusitano.

Um outro aspecto geral das críticas, nomeadamente, no âmbito historiográfico, reside no fato de que estas estão enquadradas naquilo que poderíamos chamar de «narrativas salvacionistas». Para José Gil ${ }^{(63)}$, o discurso salazarista se assemelha às narrativas canônicas das grandes sagas mitologias. O seu conteúdo divide-se segundo etapas definidas que narram a saga do Estado Novo:

[...] primeiro a situação de desordem de mentira, de anarquia, de humilhação («aviltamento») do País antes do golpe de Estado que impõe, a 28 de Maio de 1926, a Ditadura Militar. O «negativo» estende-se a todos

(59) Duarte Montalegre, «Revista do Arquivo Municipal..., cit., p. 942.

(60) António Piccarolo in Duarte Montalegre, «Revista do Arquivo Municipal..., cit., p. 942.

(61) Duarte Montalegre, «Revista do Arquivo Municipal..., cit., p. 950.

(62) Duarte Montalegre, «Revista do Arquivo Municipal..., cit., p. 951.

(63) José Gil, Salazar: a retórica da invisibilidade, Lisboa, Relógio D’Agua, 1996. 
os sectores da vida nacional: financeiro, económico social, político, moral. Mas por de trás deste passado, próximo, existe o passado longínquo, mítico, da nossa história gloriosa. O passado próximo é vulnerável como o presente, o passado distante marca um tempo forte [...] Na segunda etapa há o sacrifício financeiro, do trabalho, do capital para superar a tendência de morte, da doença para a cura ${ }^{(64)}$.

Este modelo de narração global da história do regime, desde os seus primórdios até a sua fase de regeneração e, consequente, era de ouro, não é só presente no discurso do próprio Salazar mas é reproduzido pela intelligentsia salazarista, e, também, na própria interpretação destes em relação ao Estado Novo no Brasil. Como vimos nas críticas, em particular na área de história, há sempre uma estrutura comum no que concerne a análise global do varguismo: primeiro a crise institucional ocasionada pelo liberalismo e, por, conseguinte, o despertar da nação oriundo de um Estado Novo que harmonize o conflito por meio da intervenção «regeneradora». Esta estrutura comum, no que concerne a interpretação geral do fenômeno estado-novista no Brasil e em Portugal, é um indício de uma concepção autoritária e corporativa, compartilhada por esta intelligentsia nas duas margens do Atlântico. Em ambas o herói é o próprio Estado Novo que invoca a nação a se sacrificar em prol do «ressurgimento» nacional.

Esse sacrifício não deveria ser feito somente pelo «capital»e «trabalho», mas, também pelos intelectuais que deveriam largar os seus «barroquismos» e «particularismos ideológicos» em prol de um engajamento ativo em torno da reconstrução da nação no Brasil e em Portugal. Desta forma, poderíamos dizer que há um espelhamento em torno de pelo menos quatro temas estruturantes na cultura política da intelligentsia luso-brasileira do período: a invocação de um estado forte e centralizado, a defesa de uma democracia social (por meio da organização corporativa) em detrimento de uma democracia política, a formação de uma elite engajada no processo de modernização institucional da estrutura burocrática e, por fim, a defesa intransigente de um executivo forte, e, portanto, de um crescimento da figura do estado por meio da eliminação dos «corpos intermediários», resquícios da política privatista e individualista do liberalismo.

(64) José Gil, Salazar..., cit., p. 24. 
Em suma, essa matriz comum na representação do político é objetivamente um indício de uma cultura política arraigada ao corporativismo e autoritarismo dos tempos da vaga autoritária dos anos 1920-40. O que não é arbitrário, pois, a grande maioria dos autores resenhados na Brasilia tiveram alguma relação direta ou indireta com o poder no Estado Novo brasileiro, como são os casos emblemáticos de Azevedo de Amaral, Francisco Campos e Fernando de Azevedo. Além disso, as suas obras, em sua grande maioria, foram publicadas por órgãos oficiais do regime, como o Departamento de Imprensa e Propaganda, Editora da Companhia Nacional, Comissão Brasileira dos Centenários, Seção Brasileira do Secretariado de Propaganda Nacional, Coleção Decenal da Revolução Brasileira, etc.

Tanto os autores como os resenhistas, detém uma série de vínculos institucionais diretos (com a burocracia dos regimes: militares, homens de estado) ou indiretos (por meio de órgãos da sociedade civil: universidades, bibliotecas, escolas públicas, etc.) que evidenciam uma homologia entre as suas respectivas interpretações intelectuais no âmbito pedagógico, jurídico e historiográfico com aquilo que é hegemônico no campo político, ou seja, uma visão uníssona laudatória do significado do Estado Novo. Isso, contudo, não é exclusivo da Brasilia, pois, as produções intelectuais emergidas nos anos de fortalecimento da «Política do Atlântico» (a revista Atlântico, o Boletim da Seção Brasileira do Secretariado de Propaganda Nacional, e as coleções de livro publicadas com o incentivo do Acordo Cultural de 1941) foram publicadas por órgãos oficiais que estavam em sintonia com os valores dos regimes de «terceira via».

No entanto, é preciso ressaltar que esse diálogo entre as intelectualidades e as instituições no Brasil e em Portugal, durante o Estado Novo, ultrapassou a questão do corporativismo e autoritarismo, pois, a política cultural luso-brasileira, a denominada por Antônio Ferro «Política do Atlântico», foi defendida por distintas matrizes políticas, e mesmo por aqueles que confrontavam o salazarismo. Portanto, não é ocasional que a mesma se perpetue no pós-guerra, já sobre um regime constitucionalmente democrático com sua consagração institucional na assinatura do tratado de amizade e consulta de 1953.

Entretanto, sabemos que estas relações devem ser compreendidas na sua inserção à um processo de longo prazo das relações entre Brasil e Portugal que dão um salto qualitativo e quantitativo desde a institucionalização de ambos Estados Novos, que oferece a estes 
intelectuais muito mais do que a justificativa do legado para assim se unirem em torno de uma bandeira comum: a nação luso-brasileira de matriz autoritária, corporativa e cristã contra o «satanismo» do liberalismo, comunismo e totalitarismo. Visão que tem seu lugar social no seio da revista Brasilia, e de outras revistas e produções luso-brasileiras (a despeito dos conflitos e contradições ocultadas sistematicamente nestas produções), desde o período de institucionalização do salazarismo e varguismo e afirmação das políticas culturais entre Brasil e Portugal até o fim da Segunda Guerra Mundial. 